\title{
Método Gravimétrico de Determinação de Umidade Comparativo à Determinação por Infravermelho
}

José R. Gonçalves, Wellington A. Morais, Ana Cleide dos Santos \& Renata M. Gonçalves

A validação de métodos analíticos é uma das formas de se comprovar a eficiência de uma metodologia aplicada em laboratórios de físico-química. Sendo o parâmetro "percentual de umidade e voláteis" de grande relevância em alimentos para animais, validou-se o método de determinação de umidade e voláteis por infravermelho, comparando-o com o método oficial descrito pela Portaria 108 - Métodos analíticos para controle de alimentos uso animal, de 1991- do Ministério da Agricultura, Pecuária e Abastecimento. As matrizes foram: produtos e subprodutos de origem vegetal, animal, sais minerais, rações e concentrados.

Palavras-Chave: infravermelho; umidade; validação.

The validation of analytical methods is one way to prove the efficiency of a methodology applied in physical chemistry laboratories. Being the "percentage of moisture and volatile" parameter of great importance in animal feed, validated the method of determination of moisture and volatile infrared comparing it with the official method described by Ordinance 108 - Analytical methods for food control use animal, from 1991 to the Ministry of Agriculture, Livestock and Supply. Matrices were: Products and byproducts of concentrated vegetable, animal, mineral salts, and rations.

Keywords: infrared; moisture; validation. 


\section{Introdução}

AABNT NBR ISO/IEC 17025:2005 - Requerimentos gerais para Laboratórios de Ensaio e Calibraçãodetermina diversos parâmetros para instituições que desejam implantar um Sistema de Gestão da Qualidade para sua rotina de trabalho e comprovar a eficiência analítica do trabalho realizado. Essa prevê o cumprimento de diversas exigências, citam-se como exemplos: Calibração de equipamentos, documentação atualizada e sem ambiguidades, além da melhoria contínua em vários níveis ${ }^{1}$.

Um dos requisitos da norma é a Validação de Métodos Analíticos. Essa utiliza dados estatísticos como a Análise de Variância (ANOVA), One-Way, Teste T de Student e vários outros para comprovar a eficiência de um método ${ }^{2}$.

O objetivo deste trabalho foi a validação da análise de determinação da umidade e voláteis por infravermelho em comparação ao método gravimétrico tradicional descrito na Portaria 108, métodos analíticos para controle de alimentos uso animal de $1991^{3}$. As análises aconteceram no Laboratório de Alimentos para Animais do Laboratório Nacional Agropecuário (LANAGRO) em Goiás. As matrizes que compuseram a análise foram produtos e subprodutos de origem vegetal, animal, sais minerais, rações, concentrados e ingredientes.

\section{CONCEITOS BÁSICOS DE VALIDAÇÃO}

Em sistemas de qualidade, a avaliação da eficiência de uma metodologia analítica é uma das etapas fundamentais ao processo de gestão. O principal objetivo de se avaliar um método analítico é vislumbrar se ele está adequado ao que se propõem identificar ou quantificar.

É possível utilizar várias metodologias para a determinação de algum parâmetro físico-químico, para tanto, é necessário que o procedimento seja corretamente validado. Validar é provar que um método analítico é aceito para a proposta pretendida. Mediante essa ferramenta, fatores como a imprecisão ou inexatidão do método podem ser reduzidas ou controladas. A validação de um método analítico prevê o cumprimento de vários parâmetros, quando aplicáveis, tais como: linearidade de resposta, curva de calibração, sensibilidade, limites de detecção, limites de quantificação, precisão e exatidão ${ }^{4}$.

\section{Materiais e Métodos}

\section{DETERMINAÇÃO DE UMIDADE PELO MÉTODO DE REFERÊNCIA}

De acordo com a Portaria 108 de 1991, o método de determinação de umidade aplica-se a produtos ou subprodutos de origem animal, vegetal, mineral e a rações, concentrados e ingredientes. Baseia-se na perda de umidade e substâncias voláteis à temperatura de $105^{\circ} \mathrm{C}$.

Para a marcha analítica, pesaram em cadinhos de porcelana, isentos de umidade, em torno de 2,0 g das amostras em balança analítica. Colocaram-nas em estufa, pré-aquecida a $105^{\circ} \mathrm{C}\left( \pm 1^{\circ} \mathrm{C}\right)$ até peso constante (4 a 6 horas) ou por mínimo de $6 \mathrm{~h}$. Após esse período, colocaramse as amostras no dessecador até temperatura ambiente para a pesagem final. Para a determinação do teor de umidade, utilizou-se a seguinte fórmula (método gravimétrico):

$$
\text { Umidade } \frac{\%(\mathrm{~A}-\mathrm{B})}{\mathrm{C}}=\mathrm{x} 100
$$

Onde $\mathrm{A}=$ Peso do recipiente + amostra, $\mathrm{B}=$ Peso do recipiente + amostra após secagem e $\mathrm{C}=$ Peso da amostra $^{3}$.

\section{DETERMINAÇÃO DE UMIDADE POR INFRAVERMELHO}

Para a determinação de umidade por infravermelho, utilizou-se a balança da Marca Ohaus modelo MB 200. De acordo com Park e Antônio (2007) ${ }^{5}$, a determinação de umidade procede-se como descrito a seguir: um aparelho portátil obtém resultados rápidos sobre o percentual de umidade. A amostra é colocada em um prato de alumínio, os vapores de água saem do analito e a massa é quantificada. Dentro de uma câmara, a balança de calor é protegida por meio de um colchão de ar, dessa forma, é garantida a circulação de ar interna.

Em equipamentos de secagem por infravermelho, a balança faz a leitura do conteúdo de umidade pela diferença do peso da material em estudo. Esse método mostra-se bastante eficaz, pois a penetração do calor dentro da amostra encurta o tempo de secagem em até $1 / 3$ do tempo total. Utiliza-se uma lâmpada de radiação infravermelha com 250 a 500 watts, há equipamentos que 
alcançam temperaturas de até $700{ }^{\circ} \mathrm{C}$. Quanto à distância da lâmpada à amostra, recomendam-se entre de $10 \mathrm{~mm}$ a $15 \mathrm{~mm}$, dessa forma, previne-se a decomposição do material em estudo ${ }^{6}$.

A análise gravimétrica oficial de determinação de umidade orienta que as amostras permaneçam na estufa a $105^{\circ} \mathrm{C}$, ajustou-se a balança com essa faixa de trabalho. O Tempo de permanência do alimento para animal, analisado no equipamento, foi de 20 minutos para cada amostra. Ressalta-se que é possível ajustar a temperatura e o tempo de permanência no equipamento, de acordo com a matriz trabalhada. O resultado é apresentado em porcentagem pelo próprio equipamento.

\section{IMPORTÂNCIA DA DETERMINAÇÃO DE UMIDADE EM ALIMENTOS PARA ANIMAIS}

Recomenda-se monitorar os teores de umidade em produtos destinados à alimentação animal, desde a produção, estocagem até a distribuição do produto, visto que a conservação desse está diretamente ligada a esse parâmetro Físico-Químico. Produtos úmidos oferecem condições para o desenvolvimento de microorganismos e suas toxinas. O aumento do teor de umidade deve-se, na maioria dos casos, ao fato de a estocagem ocorrer de forma incorreta, havendo, até mesmo, um amontoado do produto acabado guardado em situações impróprias.

Além dos problemas relacionados à microbiologia do alimento, o excesso deste parâmetro físicoquímico pode acarretar diluições dos nutrientes do alimento, diminuindo o valor nutritivo. Ressalta-se, porém, que baixos teores de umidade em alimentos para animais também propiciam o surgimento microorganismos ${ }^{7}$.

\section{Resultados e Discussão}

Na Tabela 1, constam os valores obtidos pelos dois métodos de determinação de umidade. Observando os resultados da tabela, percebe-se que para as mesmas amostras, são obtidos resultados bastante próximos, mesmo quando se utilizam metodologias analíticas distintas. Apesar de a tabela apresentar valores obtidos por matrizes diferentes, vislumbra-se que os valores de média e desvio padrão apresentaram-se semelhantes para os dois tipos de determinação de umidade.
Tabela 1: Resultados analíticos dos métodos gravimétrico e infravermelho para a determinação de umidade e voláteis, 2014.

\begin{tabular}{|c|c|c|}
\hline Replicatas & $\begin{array}{l}\text { Umidade e } \\
\text { Voláteis (método } \\
\text { gravimétrico) \% }\end{array}$ & $\begin{array}{c}\text { Umidade } \\
\text { e Voláteis } \\
(\text { Infravermelho } \%\end{array}$ \\
\hline 1 & 10,37 & 10,22 \\
\hline 2 & 10,13 & 10,18 \\
\hline 3 & 10,56 & 10,60 \\
\hline 4 & 10,33 & 10,70 \\
\hline 5 & 10,03 & 10,45 \\
\hline 6 & 10,79 & 10,90 \\
\hline 7 & 10,93 & 10,90 \\
\hline 8 & 10,99 & 11,00 \\
\hline 9 & 10,91 & 10,50 \\
\hline 10 & 10,85 & 10,90 \\
\hline 11 & 5,12 & 5,50 \\
\hline 12 & 5,24 & 5,40 \\
\hline 13 & 5,20 & 5,20 \\
\hline 14 & 5,07 & 5,10 \\
\hline 15 & 5,31 & 5,40 \\
\hline Média & 8,79 & 8,86 \\
\hline Desvio Padrão & 2,65 & 2,61 \\
\hline
\end{tabular}

Os dados também foram tratados estatisticamente com o "Teste T de Emparelhado" e concluiu-se que não há diferença significativa entre os métodos, ou seja, a metodologia a ser validada, determinação de umidade por infravermelho, é eficaz e aplicável à rotina laboratorial.

Ressalta-se que o objetivo da validação foi alcançado, tendo em vista que a comparação entre as duas metodologias demonstrou analiticamente e estatisticamente que o método em validação, umidade por infravermelho, quantificou de maneira satisfatória os teores de umidade das amostras, fato comprovado pelos resultados do método de referência- gravimétrico ${ }^{4}$.

\section{Conclusão}

A validação de métodos analíticos é uma ferramenta capaz de demonstrar não apenas a exatidão e a precisão de um método, mas também uma forma de propor novos caminhos para análises, ganho de tempo e/ou de reagentes, além da comprovação da eficiência do Laboratório. 


\section{Artigo Geral 3}

Por meio da validação do método de determinação de umidade e voláteis por infravermelho, percebe-se redução no tempo de análise e, quando necessária, a confirmação de resultados obtidos pelo método oficial.

Destaca-se que a validação do método analítico descrito neste artigo enquadra-se em Sistemas de Gestão da Qualidade que têm por finalidade implementar ou manter a Norma ABNT NBR ISO/IEC 17025:2005 (Requerimentos Gerais para Laboratórios de Ensaio e Calibração).

\section{Agradacimento}

Agradecemos aos Responsáveis Técnicos do Setor de Alimentos para Animais do Laboratório Nacional Agropecuário em Goiás (LANAGRO-GO) pela gentileza de permitir a realização desse artigo científico.

\section{Referências}

1. Instituto Nacional de Metrologia, Qualidade e TecnologiaInmetro. Acreditação de Laboratórios (ABNT NBR ISO/IEC 17025:2005), 2012

2. Lavra, Zênia Maria Maciel; Neto, Pedro José Rolim; SILVA Rosali Maria Ferreira da; Medeiros, Flávia Patrícia Morais de. Desenvolvimento e validação de método analítico para determinação simultânea de lamivudina, zidovudina e nevirapina em comprimidos dose-fixa combinada por cromatografia líquida de alta eficiência. Quím. Nova, v. 31, n. 5, 969-974, 2008.

3. Brasil. Ministério da Agricultura e Abastecimento (Mapa). Métodos analíticos para controle de alimentos uso animal. Portaria n ${ }^{\circ} 108$ de 04 de setembro de 1991.

4. Cotta, Jussara Aparecida Oliveira; Marques, Almir Rogério; Rezende, Maria Olímpia Oliveira; Landgraf, Maria Diva. Validação do método para determinação de nitrogênio kjeldahl total. Revista Analytica, Dezembro 2006/Janeiro 2007, №26.
5. Park, Kil Jin; Antonio, Graziella Colato. Análises de materiais biológicos, 2006

6. Heloisa, Máscia Cecchi; Fundamentos teóricos e práticos em análise de alimentos. 2. ed. revista, Editora: Unicamp, 2012.

7. Custódio, Daniel Pettersen; Brandstter, Eduardo Valcácer; Oliveira, Itamar Pereira; Oliveira, Luana Carvalho; Santos, Klayto José Gonçalves; Machado, Orlandina Ferreira; Araujo, Ailton Antônio de. Ração: Alimento animal perecível - Trabalho de revisão sobre conservação de alimento animal. Revista Eletrônica Faculdade Montes Belos, Goiás, ISSN 1808-8597, v.1, n.2, p. 131 - 147, 2005

\section{José R. Gonçalves', Wellington A. Morais², Ana Cleide dos Santos ${ }^{3}$ \& Renata M. Gonçalves ${ }^{4 *}$}

'Faculdade de Tecnologia SENAI Roberto Mange, técnico do LANAGRO-GO. Endereço: Rua da Divisa, s/n, Setor Jaó, CEP $74674-$ 025, Goiânia-GO.

${ }^{2}$ Instituto Federal Goiano, técnico e estagiário do LANAGRO-GO. Endereço: Rua da Divisa, s/n, Setor Jaó, CEP 74674-025, Goiânia-GO. ${ }^{3}$ LANAGRO-GO. Endereço: Rua da Divisa, s/n, Setor Jaó, CEP $74674-$ 025, Goiânia-GO.

${ }^{4}$ Centro de Treinamento da EMATER-GO. Rodovia R2, quadra, área, lote AR-3, Campus II-UFG, CEP 74690-815, Goiânia-GO.

*E-mail: renata.nut@gmail.com 